\title{
Fatigue Analysis for Upright of a FSAE Vehicle
}

\author{
Shobhit Agarwal, Tarun Saatyaki \\ School of Mechanical Engineering, Galgotias University
}

Gr. Noida, India

\begin{abstract}
While designing a formula car the first thing that came into mind is safety as we know a formula car experience immense mechanical loads which keep varying all through the life span of the components. It is essential to know the compatibility to ensure reliability and durability of the vehicle. This paper addresses the analysis of the Uprights for a Formula SAE vehicle and optimization of the design based on the results to increase the life. The front and rear uprights have been designed using the $3 \mathrm{D}$ modelling software SOLIDWORKS and in accordance to the formula Bharat rulebook 2020. The analysis parameters are derived from the logics and simulations of the vehicle design parameters. The study covers both static and fatigue analysis of the components with their respective boundary conditions and the analysis software used to carry out the static and fatigue analysis are Ansys Workbench. A comparison on the results obtained from the static analysis and fatigue analysis is made.
\end{abstract}

Keywords-FSAE; Upright; Soildworks; Ansys; Analysis; stress life

\section{INTRODUCTION.}

* Formula SAE is a student design competition organized by the SAE International. The event is conducted in various countries all over the world all through the year. The Formula SAE vehicle is conceptualized, designed and fabricated by the students enrolled in a university. The design of the vehicle must comply to the rulebook released by the respective competition.

* Upright is one of the most critical components in an automobile. It is the part that is connected with suspension arms (depends on the type of suspension system, in this project double wishbone type of suspension is used), the hub, brake caliper mounting and also the steering tie rod. All the loads reacted by the wheels are transmitted to the chassis through the A arms indirectly from the upright. The uprights must be sufficiently strong in order to withstand many of these forces occurring simultaneously, as well as any forces that may happen as a result of a crash or other kind of emergency without failure. Different materials are used for manufacturing these components like Aluminum alloys like 7075-T6 for light weight applications or 6061-T6 for moderate weight and moderate cost or Steel in case of low-cost applications.

\section{OBJECTIVE}

Static stress analysis is generally used by students all around the world to analyze the design of the component but it does not give the complete picture of the performance of the component.
Pushing the limits is necessary while designing a race car and reducing the safety factor of the design is generally the way adopted. On the other hand, Fatigue analysis based on the stress life approach using the variable amplitude loading simulated for the application could predict how long the component will function with the forces acting on it and helps the designer to replace the component before catastrophic failures occur.

Any optimization to the design based on the results of fatigue analysis could lead to an improvement in the life of the component which adds on to the quality of the design. The parameters used to obtain the results of the analysis are obtained by the respective calculations and analysis conducted by the team members of Automantra Racing, the official Formula Student Team of Galgotias University.

\section{LITRETURE REVIEW}

Sameer Santosh Mahadik, G.V. Acharya Institute of Engineering and Technology [1], published research paper which shows information about Caster, Camber, Scrub Radius $\&$ kingpin inclination. This paper also gives us information about various load transfers under breaking, acceleration \& impacts.

Rajendra Mane College SAE Team, MH08 Racing [2] give formulas for load transfer, breaking force \& torque.

$$
\text { Load transfer }=\frac{\text { weight } * \text { accelaration } * \text { CG height }}{\text { Trackwidth or wheel base }}
$$

The weight is the total weight supported by the two tires being analyzed. Acceleration is the gravitational force being experienced. In the case of front uprights, deceleration or centrifugal acceleration from turning. CG height is the height of the COG of the vehicle. Track width is the distance between two tires being analyzed.

It also gives us formula for calculation of braking force and torque.

\section{Braking Force $=$ Weight $*$ Deceleration force}

This formula determines the total braking force of vehicle which divides between brake calipers of FSAE vehicle.

The torque created by the braking force of that tire is determined by,

$$
\text { Torque }=\frac{\text { Brake force of wheel } * \text { Radius of tyre }}{\text { speed ratio of rotor \& tyre }}
$$

The force of each brake caliper produces a torque about the upright that it is connected to, with the moment arm being the radius of the tire. 


\section{THEORY}

Long before the LEFM approaches (e.g. Paris Law, 1961) to characterize fatigue failure were developed, the importance of cyclic loading in causing failures was recognized. The stress life approach is applicable for situations involving primarily elastic deformation. Under these conditions' component is expected to have long lifetime. If the stresses are low enough that the strains are elastic, the lifetime are likely to be long.

In real case scenarios, the mechanical components of race cars are subjected to variable amplitude loading and the loading pattern cannot be predicted with a characteristic equation. Thus, several methods have been developed over the years to take in account the variable amplitudes and using the data generated by physical tests of constant amplitude to predict the life and damage

\section{CAD MODEL OF THE DESIGN}

The uprights were designed using the $3 \mathrm{D}$ modeling software SOLIDWORKS. With the past years designs, experiences and requirements various designs were prepared to obtain a design shown below on the basis of the results obtained on static analysis for Von Mises stress, stress flow and maximum deformation. The uprights designed are required to have a high stiffness and light weight to resist the camber changes in the wheel assembly.

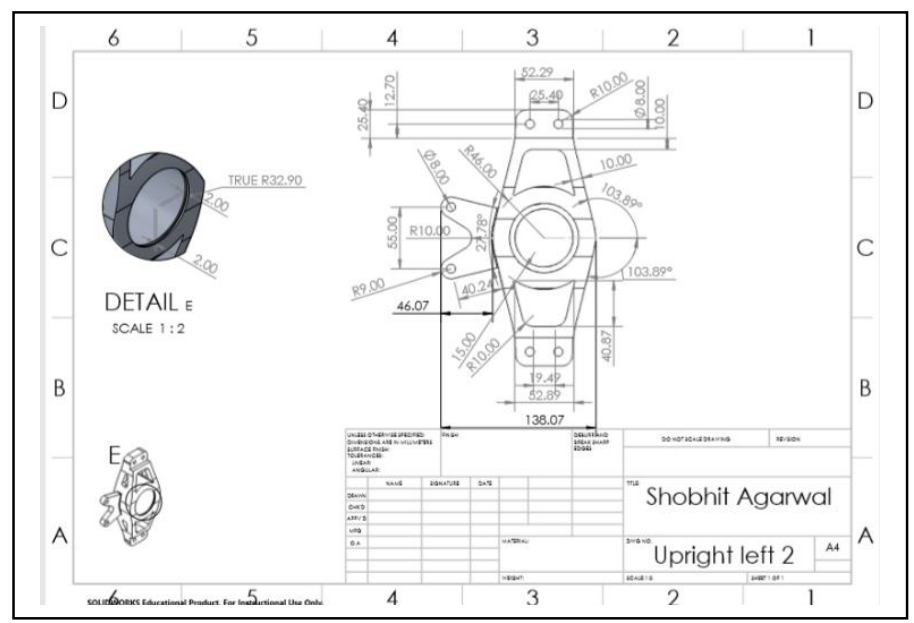

Fig. 1: CAD drawing of Upright for AR20

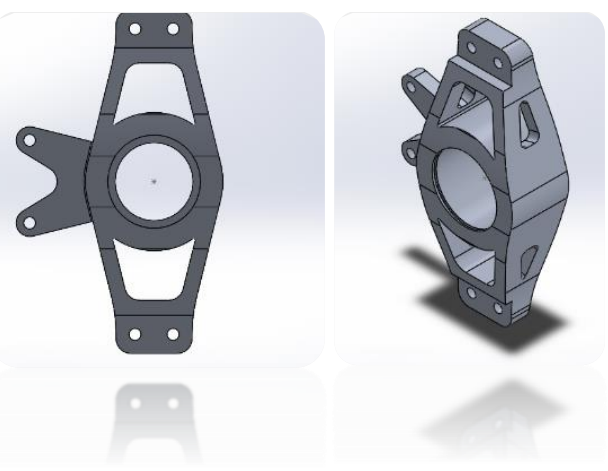

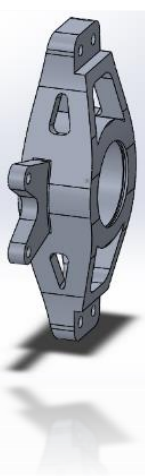

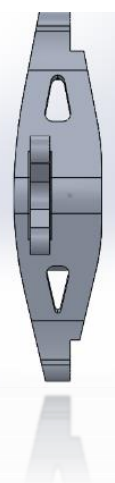

Fig. 2: CAD model of Upright for AR20

\section{MATERIAL SELECTION}

The material selected for the component is Aluminum Alloy 7075-T6 as it has a high strength to weight ratio and better fatigue properties than the other lightweight Aluminum Alloys such as 6061-T6. The properties use for the analysis were as follows:

Table 1: Material Properties of Al 6063 \& Al 7075 - T6

\begin{tabular}{|l|c|c|}
\hline \multicolumn{1}{|c|}{ Properties } & Al6061 & Al7075 \\
\hline Elastic modulus ( GPa ) & $70-80$ & $70-80$ \\
\hline Density ( g/cc ) & 2.7 & 2.81 \\
\hline Poisson's ratio & 0.33 & 0.33 \\
\hline Hardness ( HB500 ) & 30 & 60 \\
\hline Tensile strength ( MPa ) & 115 & 115 \\
\hline
\end{tabular}

Table 2: Mechanical Properties

\begin{tabular}{|c|c|}
\hline Properties & $572 \mathrm{MPa}$ \\
\hline Ultimate Tensile Strength & $503 \mathrm{MPa}$ \\
\hline Tensile yield strength & $11 \%$ \\
\hline Elongation on Break & $159 \mathrm{MPa}$ \\
\hline Fatigue strength & $25 \mathrm{MPa}-\mathrm{ml} / 2$ \\
\hline Fracture toughness & $26.9 \mathrm{GPa}$ \\
\hline Shear Module & $331 \mathrm{MPa}$ \\
\hline Shear Strength & $70 \%$ \\
\hline Machinability & $\mathrm{VS}$ \\
\hline
\end{tabular}

The log-log plot of the alternating stress vs number of cycles used for the analysis is as follows: 


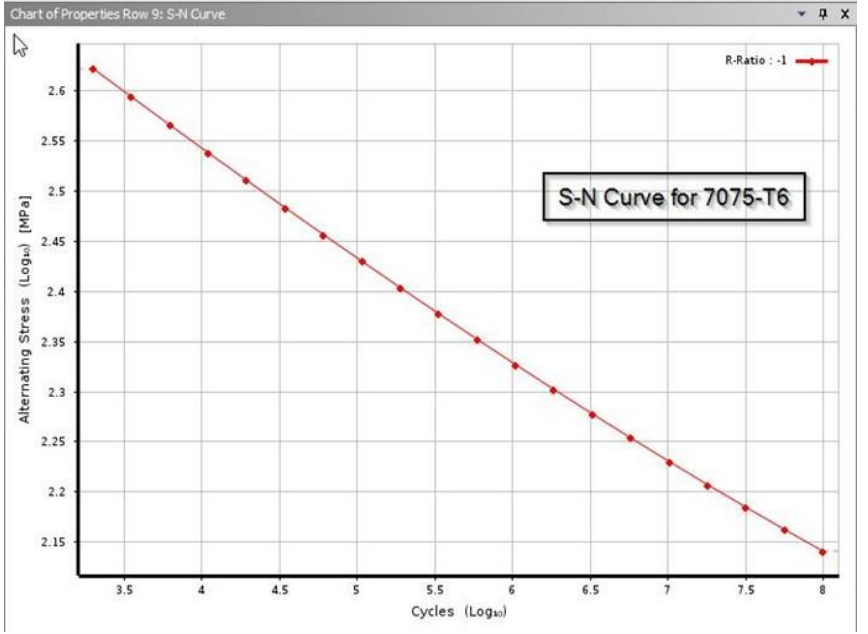

Fig. 3: S-N Curve for 7075-T6

\section{STATIC DATA}

\section{A. Static load \& boundary conditions.}

The parameters of the vehicle used for the calculation of forces for the static analysis of the front and rear uprights are:

Mass of the Car and Driver $=320 \mathrm{~kg}$

Weight Distribution $=40 / 60$

Height of Center of gravity $=310 \mathrm{~mm}$

Wheel Base $=1550 \mathrm{~mm}$

Track Width Front $=1250 \mathrm{~mm}$

Track Width Rear $=1250 \mathrm{~mm}$

Deceleration $=1.8 \mathrm{gs}$

Lateral Acceleration $=2 \mathrm{gs}$

Longitudinal Acceleration $=0.9 \mathrm{gs}$

Bump force $=1000 \mathrm{~N}$

Wheel Diameter $=457 \mathrm{~mm}$

Loads acting in all directions were calculated using below mentioned formulas [5]:

Load transfer $=\frac{\text { weight } X \text { accelaration } X C G \text { height }}{\text { Trackwidth or wheel base }}$

In $X$ Direction $=$

Longitudinal Accelaration X Load on wheel

In $Y$ Direction $=$

Lateral Accelaration X Load on wheels.

In $\mathbf{Z}$ Direction $=$

Load due to Load Transfer + Bump Forces.

Taking Moment =

Load in X during Decelerarion $X \frac{\text { Wheel Diameter }}{2}$
B. The loads carried are as follows

TABLE III.

\begin{tabular}{|l|c|c|}
\hline \multicolumn{3}{|c|}{ Load carried } \\
\hline \multicolumn{1}{|c|}{ Load Direction } & Front Upright & Rear Upright \\
\hline Load in X direction & $1128.96 \mathrm{~N}$ & $1693.44 \mathrm{~N}$ \\
\hline Load in Y Direction & $-2508.8 \mathrm{~N}$ & $-3763.2 \mathrm{~N}$ \\
\hline Load in Z direction & 2026 & 2028 \\
\hline Braking Moment & $515934 \mathrm{Nmm}$ & $773902 \mathrm{Nmm}$ \\
\hline
\end{tabular}

The assumption to carry out the analysis was that the wheel has traveled the maximum it can at the maximum load case due to bump load. The upper and lower ball joint mounting points and the tie and toe rod mounting points were given as cylindrical supports with only tangential movement free. The von mises stress and total deformation models were solved.

\section{Static Analysis Results}

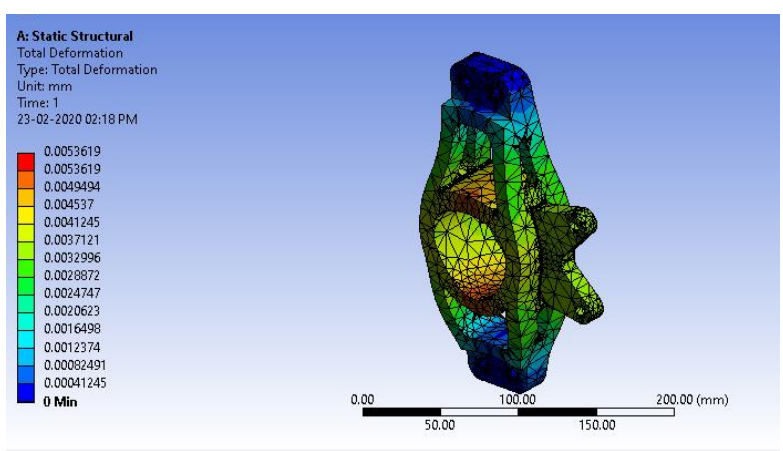

Fig 4: Total Deformation Result for upright $(\operatorname{Max}=0.00536 \mathrm{~mm})$

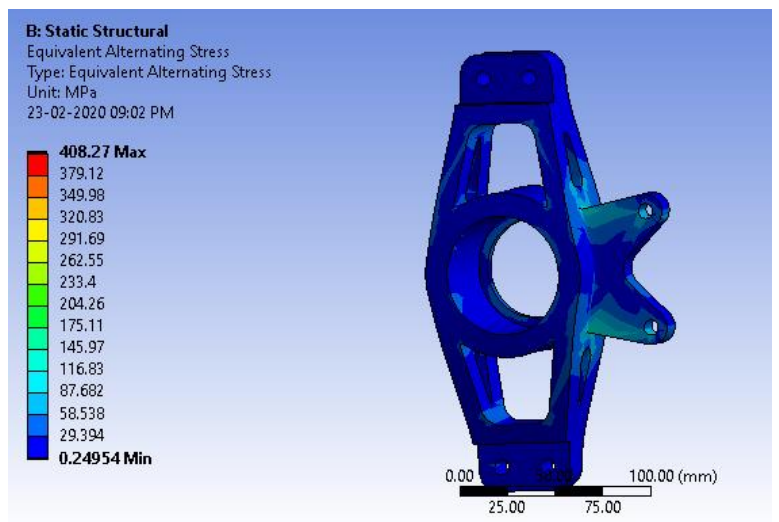

Fig 5: Maximum Principle Stress analysis for Upright (Max = 408MPa)

\section{VIII.FATIGUE ANALYSIS}

The fatigue analysis was conducted for the designs obtained using the boundary condition and loading to obtain the results for stress life. The minimum life results for the uprights were 333300 cycles respectively. The maximum cumulative damage results are also shown below. 


\section{RESULT}

The upright had a factor of safety of 1.36 from the static analysis. The minimum stress life for the Uprights were 180000 cycles or laps respectively.

\section{REFERENCES}

[1] International Journal of Current Engineering and Technology, "Design and ANSYS analysis of Components of Wheel Assembly of
SAE Car", Sameer Santosh Mahadik, E-ISSN 2277 - 4106, P-ISSN $2347-5161$

[2] IJSRD - International Journal for Scientific Research \& Development| Vol. 4, Issue 02, 2016 | ISSN (online): 2321-0613

[3] Force Calculation in Upright of a Fsae Race Car Anshul Dhakar and Rishav Ranjan Department of Mechanical Engineering, RV College of Engineering, Bangalore, India

[4] G] Milliken, W. F., and Milliken, D. L., "Race Car Vehicle Dynamics", SAE Inc. Milliken, 1995

[5] http://web.mit.edu/3.35/www/Lecture_notes/Total-Life.pdf 